Psychotherapeut $2020 \cdot 65: 208$

https://doi.org/10.1007/s00278-020-00429-7

Online publiziert: 12 . Mai 2020

(c) Springer Medizin Verlag $\mathrm{GmbH}$, ein Teil von Springer Nature 2020

\author{
Holger Richter \\ Dresden, Deutschland
}

\title{
Psyche und Psychotherapie
}

\section{Leserbrief zu}

Nikendei, C. Klima, Psyche und Psychotherapie. Psychotherapeut 65, 3-13 (2020). https:// doi.org/10.1007/s00278-019-00397-7

Der Artikel von C. Nikendei hat mich in seiner impliziten totalitären Ausrichtung schwer erschrocken.

Es steht außer Frage, dass auch Psychotherapeuten den Klimawandel thematisieren. Die unwissenschaftliche, polemische Art und die totalitären Schlussfolgerungen möchte ich kennzeichnen.

Es werden nichtfalsifizierbare Hypothesen als Prämissen gesetzt, wie etwa in der „genitalen Vermachtstellung durch Autos", die in ihrem Reduktionismus lächerlich und der Komplexität der Thematik nicht angemessen sind. Auch die "Abwehr durch Omnipotenz" ist nicht belegt; ja der Artikel selbst weist auf einen solchen Zug beim Autor hin, wenn er sich in das Gebiet der Physik und Politik wagt. Psychotherapie ist jetzt auch noch für die Bewältigung des Klimawandels zuständig.

Das Phänomen der „Echokammer“, der „Wunsch-Identität“ " und Gruppenzugehörigkeit durch Haltung zum Klimawandel gilt auch für den Autor selbst.

Dramatisierende Worte wie „Plünderung“ und „Versklavung“, die Erwähnung des Nationalsozialismus weisen auf die Abkehr von wissenschaftlicher Betrachtung hin und zeigen das Motiv: zu emotionalisieren, um dann eine bestimmte Richtung der Bewältigung des Klimawandels nahe zu legen. Nikendei zitiert eine Fake News von einem Klimaflüchtling aus Kiribati (die Anerkennung als Klimaflüchtling wurde in Wirklichkeit abgewiesen). Er stellt die nichtbewiesene These auf, dass „wir alle“ als „Täter“ traumatisiert sind, da wir mit schuldig an Kolonialismus, Rassismus, Nationalsozialismus etc. seien. Der Kommunismus wird nicht erwähnt.

Der Autor plädiert zuletzt für eine „radikale Ethik“: Er will Menschen als „Täter kennzeichnen“. Er will nicht Psychotherapeut, sondern Richter sein. Nikendei plädiert für Kollektivismus („Die bedeutsamsten und wirksamsten Optionen sind die des Kollektivs“), und das „unirritierbar". Marktwirtschaft wird abgelehnt, Sozialismus bejaht („kooperative statt kompetitive Werte“, „uns auf eine neue Gesellschaftsorganisation einstellen“ „neue, einfache und gerechte Welt") Wohin das führt, haben wir immer wieder gesehen.

Der Artikel gipfelt darin, dass ein Patient, der den Klimawandel leugnet, als „potenziell fremdgefährdend“ gesehen werden könne. Als Psychotherapeut wissen wir, was mit „Fremdgefährdern“ geschieht. Hier verlässt der Autor grundlegend den Boden demokratischer und freiheitlicher Ethik und es verwundert, dass solch ein Artikel den ethischen Standards der Herausgeber entsprechen solle.

Dr. Holger Richter, Dresden

\section{Korrespondenzadresse}

\section{Dr. Holger Richter}

Dresden, Deutschland

dr.h.richter@gmx.net

Interessenkonflikt. H. Richter gibt an, dass kein Interessenkonflikt besteht. 